Article

\title{
Pine Species That Support Crown Fire Regimes Have Lower Leaf-Level Terpene Contents Than Those Native to Surface Fire Regimes
}

\author{
Rebecca A Dewhirst ${ }^{1, *},+\mathbb{D}$, Nicholas Smirnoff ${ }^{2}$ and Claire M Belcher ${ }^{1}$ \\ 1 wildFIRE Lab, Hatherly Laboratories, University of Exeter, Prince of Wales Road, Exeter EX4 4PS, UK; \\ c.belcher@exeter.ac.uk \\ 2 College of Life and Environmental Sciences, Biosciences Geoffrey Pope Building, University of Exeter, \\ Stocker Road, Exeter EX4 4QD, UK; n.smirnoff@exeter.ac.uk \\ * Correspondence: becca.dewhirst@gmail.com; Tel.: +44-510-944-3718 \\ + Current address: Climate and Ecosystem Science Division, Lawrence Berkeley National Laboratory, \\ Berkeley, CA 94720, USA.
}

Received: 25 January 2020; Accepted: 4 June 2020; Published: 5 June 2020

\begin{abstract}
Fire is increasingly being recognised as an important evolutionary driver in fire-prone environments. Biochemical traits such as terpene (volatile isoprenoid) concentration are assumed to influence plant flammability but have often been overlooked as fire adaptations. We have measured the leaf-level flammability and terpene content of a selection of Pinus species native to environments with differing fire regimes (crown fire, surface fire and no fire). We demonstrate that this biochemical trait is associated with leaf-level flammability which likely links to fire-proneness and we suggest that this contributes to post-fire seedling survival. We find that surface-fire species have the highest terpene abundance and are intrinsically the most flammable, compared to crown-fire species. We suggest that the biochemical traits of surface fire species may have been under selective pressure to modify the fire environment at the leaf and litter scale to moderate fire spread and intensity. We indicate that litter flammability is driven not only by packing ratios and bulk density, but also by terpene content.
\end{abstract}

Keywords: crown fire; leaf-level flammability; Pinus; surface fire; terpenes; volatile compounds; wildfire

\section{Introduction}

Plants have two distinctive relationships with fire; firstly, they provide the fuel that drives the dynamics of the fire itself, secondly, they can also respond to the fire behaviour that they create in order to survive. Many plants that live in fire-prone environments are considered to have fire-related and fire-adapted traits that allow them or the next generation to survive wildfires [1]. Linkages between fire proneness and fire behaviour, and the development of fire related/adapted traits, have long been a source of major debate amongst ecologists (e.g., [1,2]). This is because of the requirement for such traits to confer a fitness advantage to the host species. For example, [1] noted that the 'evolution of flammability implies selection for traits that increase the frequency and/or intensity of fires'. Plant traits considered to enhance flammability include small leaves, presence of volatile organic compounds and retention of dead leaves and branches [1]. In particular, the presence of volatile compounds has often been considered as a flammability trait $[3,4]$, however this proposal has limited experimental evidence [5-9].

Rather than being adapted to fire in general, species are adapted to specific fire regimes that are determined by factors such as vegetation and climate [10]. Fire regimes can be broadly defined as surface 
fire (less intense fires where the leaf litter and understory shrubs burn) or crown fire (more intense wildfires where the canopy burns). Plants in crown-fire ecosystems have traits that are often described as fire adaptations. For instance, they often retain dead branches, which act as ladder fuel enabling surface fires to transition to crown fires, thus these plants have a more flammable architecture [11,12]. Plants in surface-fire ecosystems may typically shed dead branches and keep their crowns high above any surface flames, producing low tree level flammability [11]. Such traits have been grouped together as syndromes in pines, described as fire tolerator and fire avoider syndromes [13]. Pines with the fire tolerator syndrome have high litter flammability, which drives low intensity understory fires, whilst pines with the embracer syndrome are characterised by low litter flammability, but high whole tree flammability resulting in high intensity crown fires [13]. In the case of litter flammability, this has generally been considered to be due to variations in leaf length and therefore packing ratio of the leaf litter, where longer pine needles create a better aerated fuel bed, leading to a more rapid spread but shorter flame residence times $[14,15]$. However, there has been relatively little work assessing the variation in volatile content of leaves and how this might influence flammability between syndromes in pines, and therefore whether or not volatile content is part of niche construction mechanisms in fire-adapted species.

Terpenes (volatile and semi-volatile isoprenoid compounds) are the largest group of plant secondary compounds. There are three classes of volatile terpenes; monoterpenes $\left(\mathrm{C}_{10} \mathrm{H}_{16}\right.$, most volatile), sesquiterpenes $\left(\mathrm{C}_{15} \mathrm{H}_{24}\right)$ and diterpenes $\left(\mathrm{C}_{20} \mathrm{H}_{32}\right.$, least volatile). As well as roles in herbivory defence [16] and allelopathy [17], terpenes have been suggested to increase plant flammability. This is due to their low flash points allowing them to ignite easily even at relatively low concentrations and temperatures, however only a few studies have sought to empirically test this assumption $[7,8]$. Terpene content can be considered as a biochemical fire-related trait because it determines the amount of energy held within the fuel, which is critical to the energy release from the fire; meaning that the baseline chemistry of plants is a fundamental driver that fuels the combustion reaction. This chemistry determines the continued supply of reactants to the flame, hence biochemical properties likely feed up to larger scale fire behaviour, through individual elements, to the total fuel load held in an ecosystem. Despite this importance, there has been little research into how variations in biochemical traits within and among species influences leaf-level flammability and whether or not this influences litter and shoot-level flammability.

Pinus species are widespread across the Northern hemisphere, comprising more than 100 species over a range of fire regimes. Pine species store terpenes in specialised resin ducts in their leaves (needles), making them an excellent genus in which to investigate their influence on leaf-level flammability. It has been suggested that the observed high monoterpene concentrations in the needles of fire-adapted pine species may enhance needle flammability and probability of ignition [18]. In Mediterranean species, including a few Pinus species, terpene storage was found to account for up to $41 \%$ of flammability [9], and terpene content of leaf litter has been correlated to flame height as measured using an epiradiator [7]. Among species found in the Mediterranean wildland-urban interface, Pinus halepensis (the only Pinus species included in the study) was found to be the most flammable and have a high leaf terpene, particularly sesquiterpene content [6], suggesting that Pinus would be a particularly interesting genus in which to study the effect of terpenes on flammability.

Both field-based observations and genetic studies of some obligate seeder shrubs (i.e., fire embracer syndrome) suggest that their reproductive success can be linked to increased heat release and 'hot' fires stimulating post-fire recruitment [19-21]. As such, we hypothesised that needles from fire embracer pine species that dominate in crown fire regimes would have different terpene contents than surface-fire or non-fire species, and that this would alter their leaf-level flammability, based on assumptions currently made in some of the literature $[7,9,14]$. Our aim was to investigate the fundamental biochemical drivers of leaf-level flammability and their variability throughout the seasons and across pine species. To accomplish this, we measured the terpene content of needles from a selection of co-located pine trees from 13 species, throughout the year, using GC-MS 
(gas-chromatography mass-spectrometry) and, simultaneously, measured core aspects that describe their leaf-level flammability using a microcalorimeter. We contrasted this with larger scale flammability measurements using an iCone calorimeter. This allowed us to consider how plant structural properties of live fuels and needle packing in litter beds influenced flammability and, in turn, to determine whether both measures of flammability act in tandem or whether biochemical leaf traits interact with changes in structural driven flammability. While terpenes are known to be a plastic trait, varying across the environmental range [22], we have chosen to study co-located pines. This co-location allows us to have homogenous environmental conditions and remove climate as a variable, and thus minimise any environmental effect on terpene content. Equally, past exposure to fire can alter terpene production, with three Mediterranean Pinus species showing lower terpene production one year post-burn, compared to pre-burning levels [23]. To the best of our knowledge, none of the trees in the current study have experienced fire, thus removing this effect as a short-term variable. The aim of this study is to investigate the evolutionarily determined traits of flammability and terpene content of trees currently native to different fire regimes. As an example, the evolution of other fire-adapted traits such as serotiny and branch-shedding can be traced back to the Cretaceous (89 Ma) [24], highlighting the relevance of this evolutionary view.

\section{Materials and Methods}

\subsection{Sampling Pine Species}

Needles from mature Pinus species (Table 1; P. radiata, P. muricata, P. densiflora, P. banksiana, P. sylvestris, P. monticola, P. greggii, P. engelmannii, P. flexilis, P. nigra, P. strobus, P. wallichiana and P. patula) were collected from the grounds of Streatham Campus, University of Exeter, UK. Sample collections were carried out on three occasions; November 2016 (winter), April 2017 (spring) and August 2017 (summer) to investigate seasonal differences in terpene levels and flammability. All trees were mature and of similar age, being planted as part of a botanic garden started by horticulturist James Veitch at the University of Exeter. For each species, three samples from an individual were collected at each time point. The needles were analysed for terpenes and flammability measurements immediately ('fresh') or in a fully cured state by drying at $40^{\circ} \mathrm{C}$ for several weeks ('lab-dried') before analysis. The leaf-level flammability and terpene analyses were carried out simultaneously in both states, to make sure that no time-based variations occurred. Lab-dried needles were used as a proxy for leaf litter, although there may be some differences between our lab-dried needles and true leaf litter, in which some compounds will likely have degraded due to microbial metabolism.

Table 1. Pine species, traits and fire regimes. Information in this table is adapted from He et al. (2012).

\begin{tabular}{|c|c|c|c|c|c|c|}
\hline Species & Fire Regime & Subgenera & Serotiny & Branch Retention & Resprouting Ability & Native Fire Season \\
\hline P. banksiana & Crown & Pinus & Yes & Yes & No & Summer \\
\hline P. densiflora & None & Pinus & No & Yes & No & N/A \\
\hline P. engelmannii & Surface & Pinus & No & No & No & Spring \\
\hline P. flexilis & None & Strobus & No & No & No & N/A \\
\hline P. greggii & Crown & Pinus & Yes & Yes & No & Spring \\
\hline P. monticola & None & Strobus & No & No & No & $N / A$ \\
\hline P. muricata & Crown & Pinus & Yes & Yes & No & Autumn \\
\hline P. nigra & Surface & Pinus & No & Yes & No & Summer \\
\hline P. patula & Crown & Pinus & Yes & Yes & Yes & Spring \\
\hline P. radiata & Crown & Pinus & Yes & Yes & No & Autumn \\
\hline P. strobus & Surface & Strobus & No & No & No & Summer \\
\hline P. sylvestris & Surface & Pinus & No & No & No & Spring/summer \\
\hline P. wallichiana & Surface & Strobus & No & Yes & No & Spring \\
\hline
\end{tabular}

We categorised the pine species according to their typical current native fire regime such that they were grouped into those considered as either: crown-fire, surface-fire or non-fire, as defined by [24] (Table 1). The leaf-level flammability and terpene analyses were conducted on fresh needle samples (representative of crown fires, where a large proportion of living tissue on the tree burns) and on lab-dried needles (representative of leaf litter which provides fuel in surface fires). The larger 
scale flammability tests of shoots from a sub-set of the pine trees were conducted on dried material to consider not only the scaling of biochemical traits, but also to assess the potential influences of branch shedding (fire tolerator syndrome) versus dead branch retention (fire embrace syndrome).

\subsection{Terpene Analysis}

Terpenes were extracted from both fresh and lab-dried needles ground with a pestle and mortar under liquid nitrogen in n-hexane ( $0.05 \mathrm{~g}$ (fresh weight) in $5 \mathrm{~mL}$ with butylated hydroxytoluene as an internal standard) by sonication and subsequent overnight incubation (modified protocols from $[7,25]$ ). Samples were analysed using an Agilent 7200 series accurate mass Q-TOF mass spectrometer coupled to a 7890A GC system (Agilent Technologies, Santa Clara, USA), equipped with an EI (electron ionisation) ion source. $5 \mu \mathrm{L}$ of each sample was injected into a non-deactivated, baffled glass liner with a 12:1 split ratio (14.448 ml min ${ }^{-1}$ split flow) and the inlet temperature was maintained at $250{ }^{\circ} \mathrm{C}$. A Zebron semi-volatiles (Phenomenex, Torrance, USA) column $(30 \mathrm{~m} \times 250 \mu \mathrm{m} \times 0.25 \mu \mathrm{m})$ coupled with a $10 \mathrm{~m}$ guard column, was maintained at a constant helium flow of $1.2 \mathrm{~mL} \mathrm{~min}^{-1}$. The temperature of the column was ramped up at a rate of $15^{\circ} \mathrm{C} \mathrm{min}-1$, from $70{ }^{\circ} \mathrm{C}$ to $310{ }^{\circ} \mathrm{C}$ over $16 \mathrm{~min}$, and then held at $310{ }^{\circ} \mathrm{C}$ for a further $6 \mathrm{~min}$. The EI source emission current and emission voltage were held at $35 \mu \mathrm{A}$ and $70 \mathrm{eV}$, respectively. The mass range was set from 50 to $600 \mathrm{~m} / \mathrm{z}$, with an acquisition rate of 5 spectra s ${ }^{-1}$, and a solvent delay of $4 \mathrm{~min}$. Data were analysed using Agilent MassHunter Quantitative Analysis software (version B.07.00) and compounds identified by comparison with known standards and with NIST (NIST 11 Mass Spectral Library) and Golm libraries [26]. Where it was not possible to conclusively identify the individual compound, the identity as either mono- $\left(\mathrm{C}_{10} \mathrm{H}_{16}\right)$, sesqui- $\left(\mathrm{C}_{15} \mathrm{H}_{24}\right)$ or di-terpene $\left(\mathrm{C}_{20} \mathrm{H}_{32}\right)$ was inferred from the presence of characteristic ions $(\mathrm{m} / \mathrm{z} 93,91,105$ and 121), retention time and suggested identities from the GC-MS libraries. The three terpene fractions were quantified by peak area relative to the $10 \mu \mathrm{M} \alpha$-pinene standard.

\subsection{Leaf-Level Flammability Measurements}

The leaf-level flammability was measured using a Federal Aviation Administration (USA, FAA) microcalorimeter (Fire Testing Technology, East Grinstead, UK) that was developed to allow direct measurements of heat release rate with respect to the material properties and chemical composition of materials [27]. The FAA microcalorimeter is a pyrolysis combustion flow calorimeter and was used to reproduce the solid-state and gas phase processes of flaming combustion by heating 10-15 mg samples of each pine needle in a nitrogen stream, whereupon the volatile gases are driven off and oxidised at high temperature in excess oxygen. The microcalorimeter then measures the rate of heat release based on the oxygen consumption history of the fuel. The samples were exposed to a heating program that ramped up to $750{ }^{\circ} \mathrm{C}$, at a rate of $3^{\circ} \mathrm{C}$ per second. Each sample was analysed in triplicate. The maximum temperature (Temp: the temperature at which the maximum rate of decomposition of virgin fuel is reached), peak heat release (pHRR: the most intense flux of heat during the combustion of the leaf material, this indicates the maximum decomposition rate of the leaves which is related to the volatile gas flux of the material), heat capacity (HRC: the maximum capability of the leaf material to release combustion heat per degree of temperature during pyrolysis; this measure provides an indication of the resistance of the leaves to thermal degradation) and total heat release (THR: the total energy released by the leaf during combustion) was determined for each leaf on a $\mathrm{g}^{-1}$ dry mass basis. Three independent samples were taken at each seasonal time point for each species tested; a total of 5 species from both surface and crown fire regimes, as well as 3 from non-fire regimes, were tested. All energy release-based measurements were calculated by the software native to the microcalorimeter. Figure S1a shows examples of the output from the microcalorimeter.

\subsection{Branch and Needle Fuel Bed Larger-Scale Flammability Measurements}

Flammability was measured using an iCone calorimeter (Fire Testing Technology, East Grinstead, UK). This apparatus is an international standard in experimental fire testing (ISO 5660-Part 1; ASTM 
E1354) for the measurement of heat release under controlled laboratory conditions, and has been used for experimental plant flammability protocols as in $[28,29]$. Small branches were removed from trees and dried at $40{ }^{\circ} \mathrm{C}$ for 4 days. The dried branches ensured ignition during this experimental set-up (fresh samples did not ignite) and were representative of dead and drying branches on the tree, which ignite quickest during a fire. Sections (approximately $10 \mathrm{~cm}$ in length) were placed upright into a metal basket perforated on the base and sides (as in Figure 1) and subjected to a heat flux of $50 \mathrm{~kW}$. Needle fuel beds were prepared by filling a metal basket, $15 \mathrm{~cm}$ wide and $3 \mathrm{~cm}$ deep (volume of $368 \mathrm{~cm}^{3}$ ) with dried needles according to the natural needle packing density. We used equal volumes of fuel, which meant that full baskets ranged from $\sim 5$ to $8 \mathrm{~g}$ in weight. Needles were added to the basket without compression or forced over-filling in order to maintain a natural packing density. Three individual replicates from three representative species, one from each of the fire regimes, were used ( $P$. radiata from the crown fire species, P. sylvestris from surface fire and P. monticola from non-fire). The baskets were subjected to a $50 \mathrm{~kW}$ heat flux. In both cases, the heat flux was delivered from a high-powered cone-shaped coiled heating element (e.g., Figure 1). This was positioned above the samples for needle flammability measurements and beside the samples for branch flammability measurements. The iCone calorimeter monitors oxygen depletion above the sample, where the heat released during combustion per unit mass of oxygen consumed is a constant [30]. Using the iCone, we measured the peak heat release rate, total heat release and the duration of burning for each sample (Figure S1b). All of these quantitative measures are calculated by the software native to the iCone calorimeter.

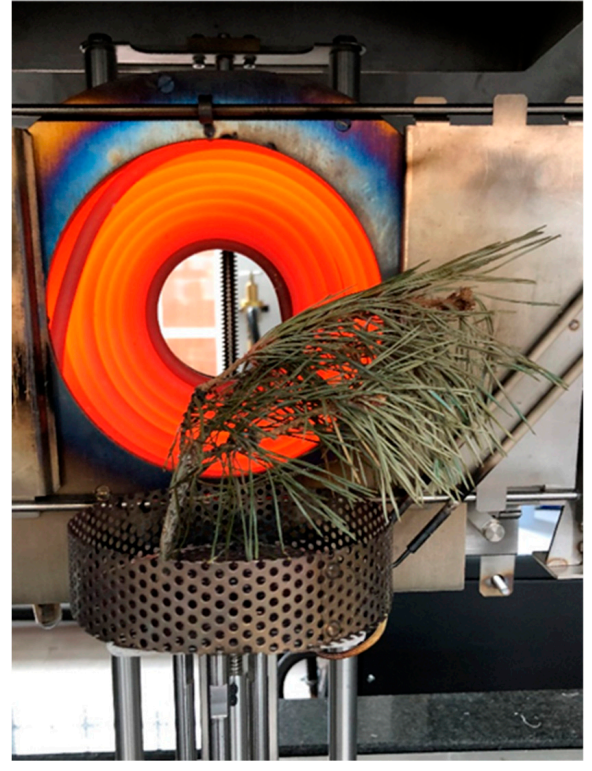

(a)

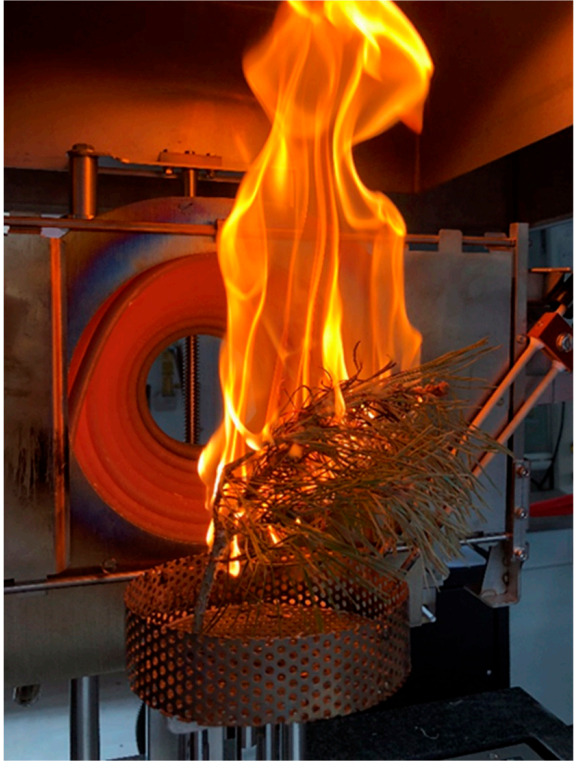

(b)

Figure 1. Example of testing branch-level flammability. A section of a branch (approximately $10 \mathrm{~cm}$ in length) was fixed in a metal basket (a). The sample was subjected to a $50 \mathrm{~kW}$ heat flux from the cone-shaped heating element, resulting in ignition $(\mathbf{b})$.

\subsection{Statistical Analyses}

Kruskal-Wallis with Wilcoxon rank sum test statistical analyses of leaf-level flammability and terpene content were carried out in $\mathrm{R}$ version 3.6.0 to determine significant differences between fire regimes. Samples were categorised into their native fire regime [24] within each season. Each group consisted of three replicate samples for each species at each timepoint $(\mathrm{n}=15$ for crown-fire and surface-fire groups; $\mathrm{n}=9$ for non-fire group). All $\mathrm{p}$ values stated are from the Kruskal-Wallis analysis, and exact $p$ values are stated unless the value is below 0.0001 . 
PCA analysis was carried out in MetaboAnalyst (metaboanalyst.ca, [31]) using the same data and groupings as Kruskal-Wallis analysis, with the aim of determining the factors that best described the differences between fire regimes. The data were normalised by log transformation and auto-scaled (mean centred and divided by the standard deviation of the variable) before PCA.

\section{Results}

\subsection{Terpene Content of Pine Species from Different Fire Regimes}

Fresh needles of crown-fire species were found to have significantly lower overall terpene levels than surface-fire ( $p=0.0011$ summer, $p<0.0001$ winter, and spring $p<0.0001$ Kruskal-Wallis) and non-fire ( $p<0.0001$ winter, $p=0.0005$ summer, $p=0.0002$ spring) species (Figure 2a) across all the seasons.
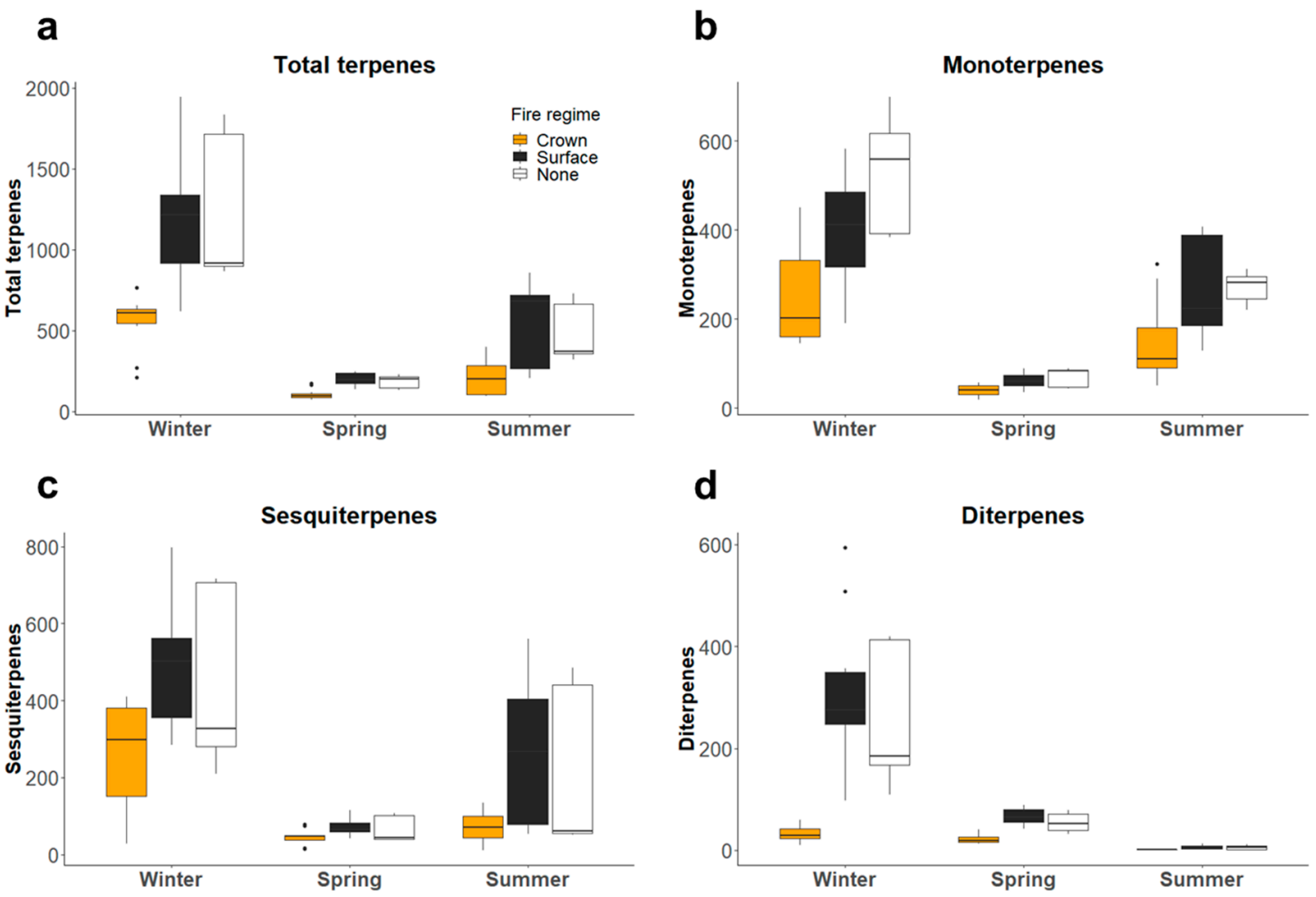

Figure 2. Terpene content of fresh pine needles. The terpene content, determined by gas-chromatography mass-spectrometry (GC-MS) analysis, of fresh needles of pine species, grouped by fire regime and season, are shown. Terpene concentration ((a) - total terpenes; (b) - monoterpenes; (c)—sesquiterpenes; (d) - diterpenes) are reported in relative abundance (total peak area relative to $\alpha$-pinene standard per gram dry weight). The boxes represent the interquartile range, with the median indicated; $\mathrm{n}=15$ (crown), 15 (surface) and 9 (none), with five species from both crown and surface fire regimes and three non-fire species, for each season.

The pattern observed with fresh needles was repeated in lab-dried needles (Figure 3), with significant differences between crown-fire and surface-fire ( $p=0.0002$ spring, $p<0.0001$ winter, $p=$ 0.0158 summer) and between crown-fire and non-fire ( $p<0.0001$, winter, $p=0.0083$, spring, $p=0.0220$ summer). The total terpene levels were similar between surface-fire and non-fire species in both fresh (Figure 2a) and lab-dried needles (Figure 3a). 

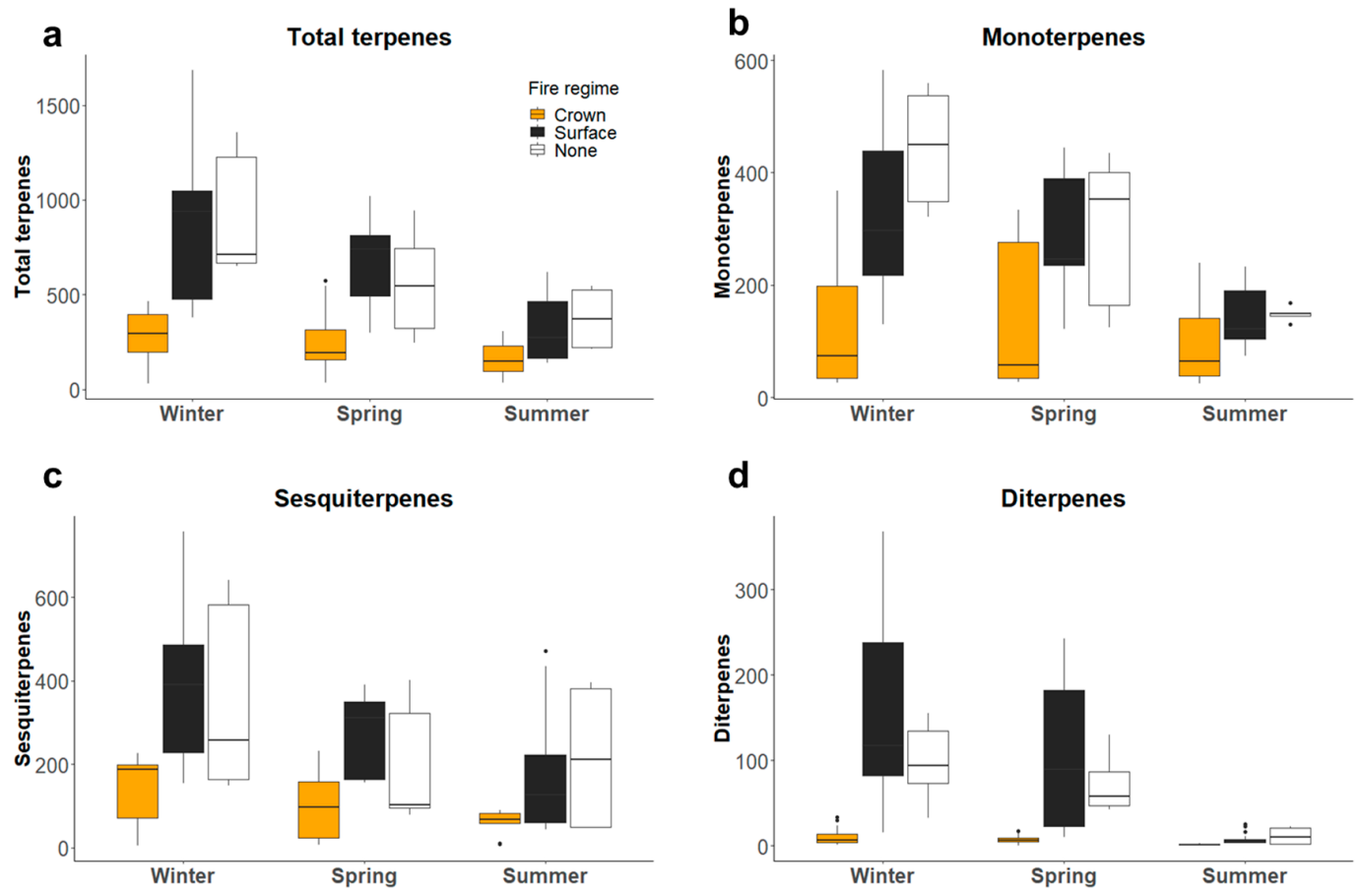

Figure 3. Terpene content of lab-dried pine needles. The terpene content, determined by GC-MS analysis, of lab-dried needles of pine species, grouped by fire regime and season, are shown. Terpene concentration ((a) - total terpenes; (b)-monoterpenes; (c)-sesquiterpenes; (d)-diterpenes) are reported in relative abundance (total peak area relative to $\alpha$-pinene standard per gram dry weight). The boxes represent the interquartile range, with the median indicated; $n=15$ (crown), 15 (surface) and 9 (none), with five species from both crown and surface fire regimes and three non-fire species, for each season.

This pattern was repeated for individual terpene classes with fresh needles, with crown-fire species having significantly lower monoterpene ( $p=0.0019$ summer, $p=0.0041$ winter, $p=0.0026$ spring), sesquiterpene ( $p=0.0054$ summer, $p=0.0054$ winter, $p=0.0070$ spring) and diterpene ( $p<0.0001$ winter, $p<0.0001$ summer, $p<0.0001$ spring) levels than surface-fire species (Figure $2 \mathrm{~b}-\mathrm{d}$ ). In dried needles, crown-fire species had lower monoterpene content in spring $(p=0.0160)$ and winter $(p=0.0046)$ than surface-fire species. This was also the case for sesquiterpenes ( $p=0.0004$, spring; $p=0.0006$ winter) and diterpenes ( $p<0.0001$ for spring, summer and winter). The differences between crown-fire and surface-fire monoterpenes and sesquiterpenes in summer were not statistically significant.

Although this pattern persists across the seasons, there are marked differences in seasonal terpene abundance (Figures 2 and 3). Non-fire species had higher total terpene levels than crown fire species but, on average (median), lower terpene levels than surface fire species in both fresh (Figure 2a) and lab-dried (Figure 3a) needles. However, when the terpene classes are considered separately, non-fire species were found to have high monoterpene contents, particularly in the winter and summer, where in these months the leaf monoterpene levels were on average (median) higher than pines typical of surface fire regimes (Figure 2b). The median abundance of sesquiterpenes and diterpenes in non-fire species was found to be similar to species originating from crown fire regimes (Figure 2c,d).

Overall total terpene content was much higher in winter, with the lowest overall terpene levels in spring. This was also the case for monoterpenes and sesquiterpenes (Figure 2b,c). Conspicuously, diterpene levels were lowest in summer in the fresh needles (Figure 2d). Lower overall terpene levels in spring and summer correspond with the native fire season for many of the species (Figures 2a and 3a and Table 1). Analysis of the total terpene content of individual species highlights the difference between crown and surface fire species, with crown fire species having consistently lower terpene levels (Figure S2). 


\subsection{Leaf-Level Flammability Measurements}

Crown-fire species (Figure S4a) had a lower peak heat release rate as well as total heat release than that of the surface fire species (Figure S4b). Indeed, when considering all of the species tested, we reveal that the fresh-needle leaf-level flammability parameters of heat release capacity (a measure of a material's resistance to fire, where lower numbers indicate increased fire resistance; Figure 4a), peak heat release rate (maximum energy release, relating to fire intensity; Figure $4 \mathrm{~b}$ ) and total heat release (total energy released; Figure 4c) are lower in crown-fire species than surface-fire species. Summer samples were shown to exhibit considerably lower flammability than at other times of the year (e.g., Figure 4). Crown-fire species showed significantly lower flammability than surface-fire in the summer (heat release capacity: $p=0.0078$; peak heat release rate: $p=0.0031$; total heat release: $p=0.0014$ ). Interestingly, the leaves of the non-fire species appeared to be the least resistant to fire when compared to crown and surface fires during both the spring and summer (Figure $4 \mathrm{~b}$ ). The temperature at which the maximum decomposition of the sample occurs did not differ significantly between the fire regimes within each season (Figure 4d). However, there were some seasonal differences in this measure; surface fire species had a significantly higher temperature of maximum decomposition in winter compared to summer $(p=0.002)$ and spring $(p=0.0021)$.
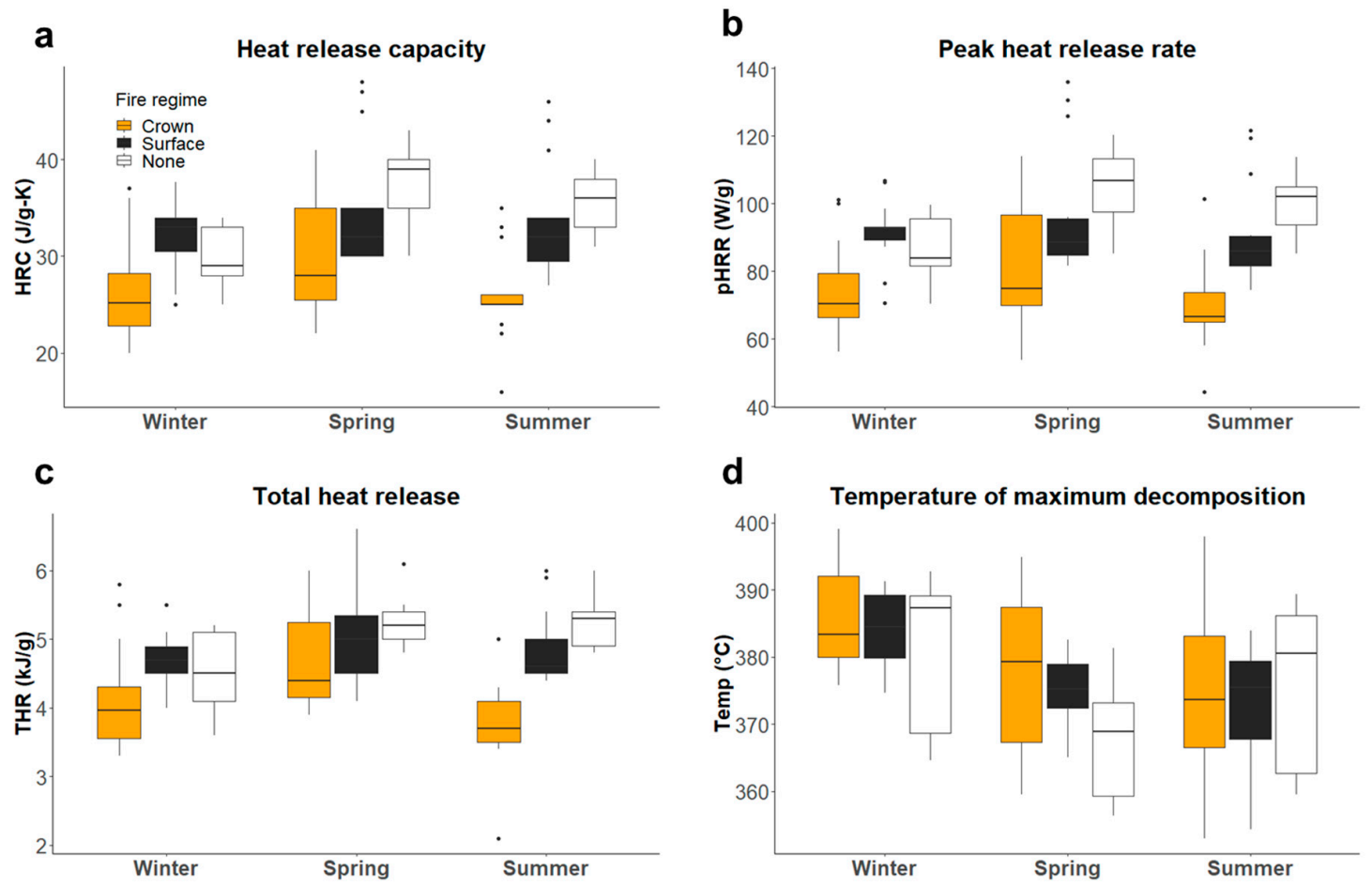

Figure 4. Flammability measurements of fresh pine needles. The flammability characteristics of fresh needles of pine species, grouped by fire regime and season, are shown. The flammability characteristics were determined by microcalorimetry analysis ((a) — heat release capacity; (b) - peak heat release rate; (c) — total heat release; (d) - temperature of maximum decomposition). The boxes represent the interquartile range, with the median indicated; $n=15$ (crown), 15 (surface) and 9 (none), with five species from both crown and surface fire regimes and three non-fire species.

Our analysis of lab-dried needles followed the same overall pattern as the fresh needles described here for the surface and crown fires species, but the non-fire species became similar to the surface species when dried (Figure 5). Both the peak heat release rate (Figure 5b; $p=0.0012$ in winter, $p=$ 0.0113 in spring, $p=0.0293$ in summer) and total heat release (Figure $5 c ; p=0.0063$ in winter, $p=$ 0.0137 in spring and $p=0.0137$ in summer) were significantly lower in crown-fire species compared to 
surface-fire species across all seasons. The heat release capacity of crown-fire species was significantly lower than that of surface-fire species in winter (Figure 5a; $p=0.005)$ and summer $(p=0.032$ ).
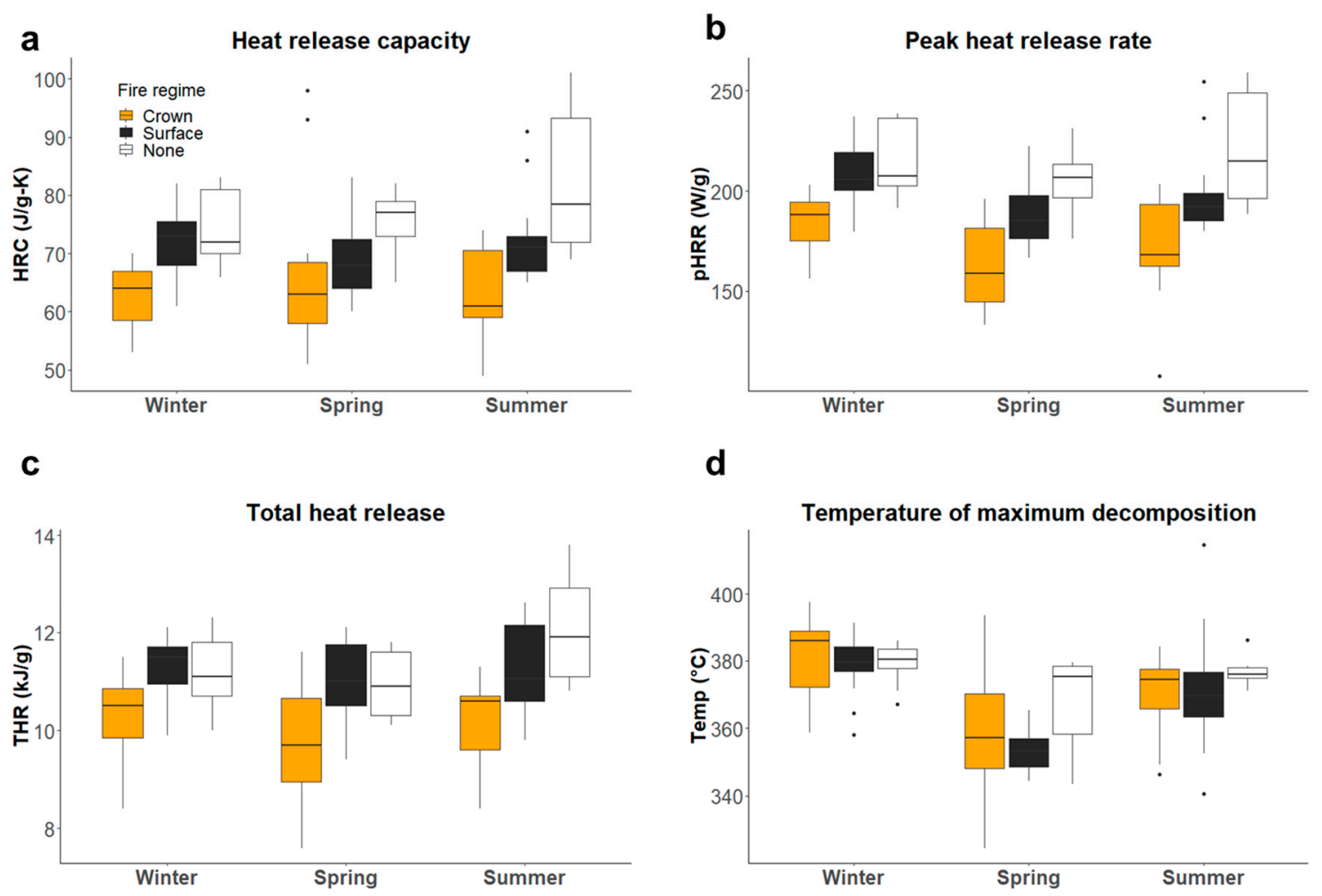

Figure 5. Flammability measurements of lab-dried pine needles. The flammability characteristics of lab-dried needles of pine species, grouped by fire regime and season, are shown. The flammability characteristics were determined by microcalorimetry analysis ((a) — heat release capacity; (b) — peak heat release rate; (c) — total heat release; (d)—temperature of maximum decomposition). The boxes represent the interquartile range, with the median indicated; $n=15$ (crown), 15 (surface) and 9 (none), with five species from both crown and surface fire regimes and three none fire species.

\subsection{Correlations between Leaf-Level Flammability and Terpene Content}

Pearson correlations, using data from all the seasons, show that there are significant relationships between terpenes and leaf-level flammability. Specifically, in fresh samples of the needles (Table 2), sesquiterpenes were significantly positively correlated with both heat release capacity and peak heat release rate (as measured in the microcalorimeter). With samples of the lab-dried needles (Table 3), there were more correlations that were significant; both monoterpenes and sesquiterpenes were correlated with heat release capacity, peak heat release rate and total heat release. Diterpenes were also positively correlated with peak heat release rate and total heat release in dried needles. These correlations provide further evidence for a link between terpene content and leaf-level flammability. We also note that terpene content across the individual terpene classes correlates with each other. Equally, HRC, pHRR and THR are correlated, but these flammability metrics are not correlated with temperature of maximum decomposition in fresh needles; but, with lab-dried needles, Temp is correlated with pHRR and THR (Table 3). Fuel moisture content is important for flammability, however, the use of lab-dried samples removed fuel moisture content as a variable, and with fresh needles the fuel moisture content did not vary between assigned fire regimes (Figure S5). 
Table 2. Table showing Pearson correlations between terpene and flammability measurements for fresh needles across all seasons $(n=117)$. Significant correlations are in bold and the level of significance is indicated with asterisks $\left(* * p<0.01 ;{ }^{*} p<0.05\right)$.

\begin{tabular}{|c|c|c|c|c|c|c|c|c|}
\hline & Monoterpenes & Sesquiterpenes & Diterpenes & Total Terpenes & HRC & pHRR & THR & Temp Max \\
\hline Monoterpenes & 1 & & & & & & & \\
\hline Sesquiterpenes & $0.613^{* *}$ & 1 & & & & & & \\
\hline Diterpenes & $0.518^{* *}$ & $0.574^{* *}$ & 1 & & & & & \\
\hline Total terpenes & 0.840 ** & 0.897 ** & $0.788^{* *}$ & 1 & & & & \\
\hline HRC & 0.089 & $0.187^{*}$ & 0.141 & 0.168 & 1 & & & \\
\hline pHRR & 0.143 & 0.233 * & $0.202 *$ & $0.230 *$ & $0.982 * *$ & 1 & & \\
\hline THR & 0.129 & 0.163 & 0.178 & 0.184 * & $0.927 * *$ & $0.915^{* *}$ & 1 & \\
\hline Temp max & 0.165 & 0.146 & 0.134 & 0.175 & -0.056 & -0.037 & -0.033 & 1 \\
\hline
\end{tabular}

Table 3. Pearson correlations between terpene and flammability measurements for lab-dried needles across all seasons $(\mathrm{n}=117)$. Significant correlations are in bold and the level of significance is indicated with asterisks $\left(* * p<0.01{ }^{*} p<0.05\right)$.

\begin{tabular}{|c|c|c|c|c|c|c|c|c|}
\hline & Monoterpenes & Sesquiterpenes & Diterpenes & Total Terpenes & HRC & pHRR & THR & Temp Max \\
\hline Monoterpenes & 1 & & & & & & & \\
\hline Sesquiterpenes & $0.655^{* *}$ & 1 & & & & & & \\
\hline Diterpenes & $0.652 * *$ & $0.692 * *$ & 1 & & & & & \\
\hline Total terpenes & $0.886^{* *}$ & $0.913 * *$ & $0.831 * *$ & 1 & & & & \\
\hline HRC & $0.295 * *$ & $0.391 * *$ & 0.084 & $0.333 * *$ & 1 & & & \\
\hline pHRR & $0.320 * *$ & $0.459 * *$ & $0.208^{*}$ & $0.403 * *$ & $0.750 * *$ & 1 & & \\
\hline THR & $0.241^{* *}$ & $0.449 * *$ & 0.207 * & $0.364^{* *}$ & $0.576^{* *}$ & $0.803^{* *}$ & 1 & \\
\hline Temp max & 0.048 & 0.098 & 0.073 & 0.084 & 0.097 & $0.447^{* *}$ & $0.376^{* *}$ & 1 \\
\hline
\end{tabular}

Principal components analysis (PCA) of the data revealed that the terpene and leaf-level flammability signatures of crown-fire species consistently grouped together (Figures 6 and 7), highlighting that the fire-related leaf traits hosted by the crown species are distinctive when compared to those species that are prevalent in surface and non-fire regimes. PCA plots of the spring and summer data (Figures 6 and 7) are shown, as these seasons represent the fire season for the majority of the species, but the pattern continues in winter (Figure S4). With fresh needles (Figure 6), the separation of crown-fire species from surface and non-fire species occurs along the principal component 1 axis, which accounts for $46.4 \%$ of variance for fresh spring needles (Figure $6 \mathrm{a}$ ) and $54.3 \%$ for fresh summer needles (Figure 6c). For fresh needles, the PC1 axis is predominantly comprised of the following flammability characteristics: heat release capacity, peak heat release rate and total heat release (Figure $6 \mathrm{~b}, \mathrm{~d}$ ).

For lab-dried needles, PC1 accounts for $47.9 \%$ of the variance of spring needles, and $54.3 \%$ for summer. With spring lab-dried needles, peak heat release rate and total heat release, along with diterpene and monoterpene levels, had the most influence (Figure $7 \mathrm{~b}$ ). For the summer lab-dried needles, the PC1 axis was predominantly characterised by heat release capacity, peak heat release rate and total heat release, along with sesquiterpene levels (Figure 7d).

\subsection{Shoot and Litter Level Flammability Measurements}

These leaf-level flammability measurements demonstrate differences in the fundamental flammability of the needles between pines that group into different fire syndromes. We scaled up the flammability experiments to consider how leaf-level flammability might interact with morphological differences of both shoot structure in small branch sections, with regards to dead branch retention vs branch shedding and as leaf litter (Figure 8). The peak heat release rate, which corresponds to the maximum fire intensity, of the branch sections of crown-fire species was lower than that of surface-fire species (Figure $8 \mathrm{a}, \mathrm{c} ; 415.3 \pm 46.6 \mathrm{~kW} / \mathrm{m}^{2}$ compared to $625.7 \pm 121.8 \mathrm{~kW} / \mathrm{m}^{2}$ ) as was that of the non-fire species (Figure 8e, $511.8 \pm 195.0 \mathrm{~kW} / \mathrm{m}^{2}$ ). The total heat release was also lower from crown-fire species branches than surface-fire species $\left(4.50 \pm 1.5 \mathrm{MJ} / \mathrm{m}^{2}\right.$ compared to $\left.12.65 \pm 0.8 \mathrm{MJ} / \mathrm{m}^{2}\right)$. The non-fire species showed total heat release (Figure $8 \mathrm{e} ; 4.79 \pm 2.1 \mathrm{MJ} / \mathrm{m}^{2}$ ) similar to that of the crown-fire species. 

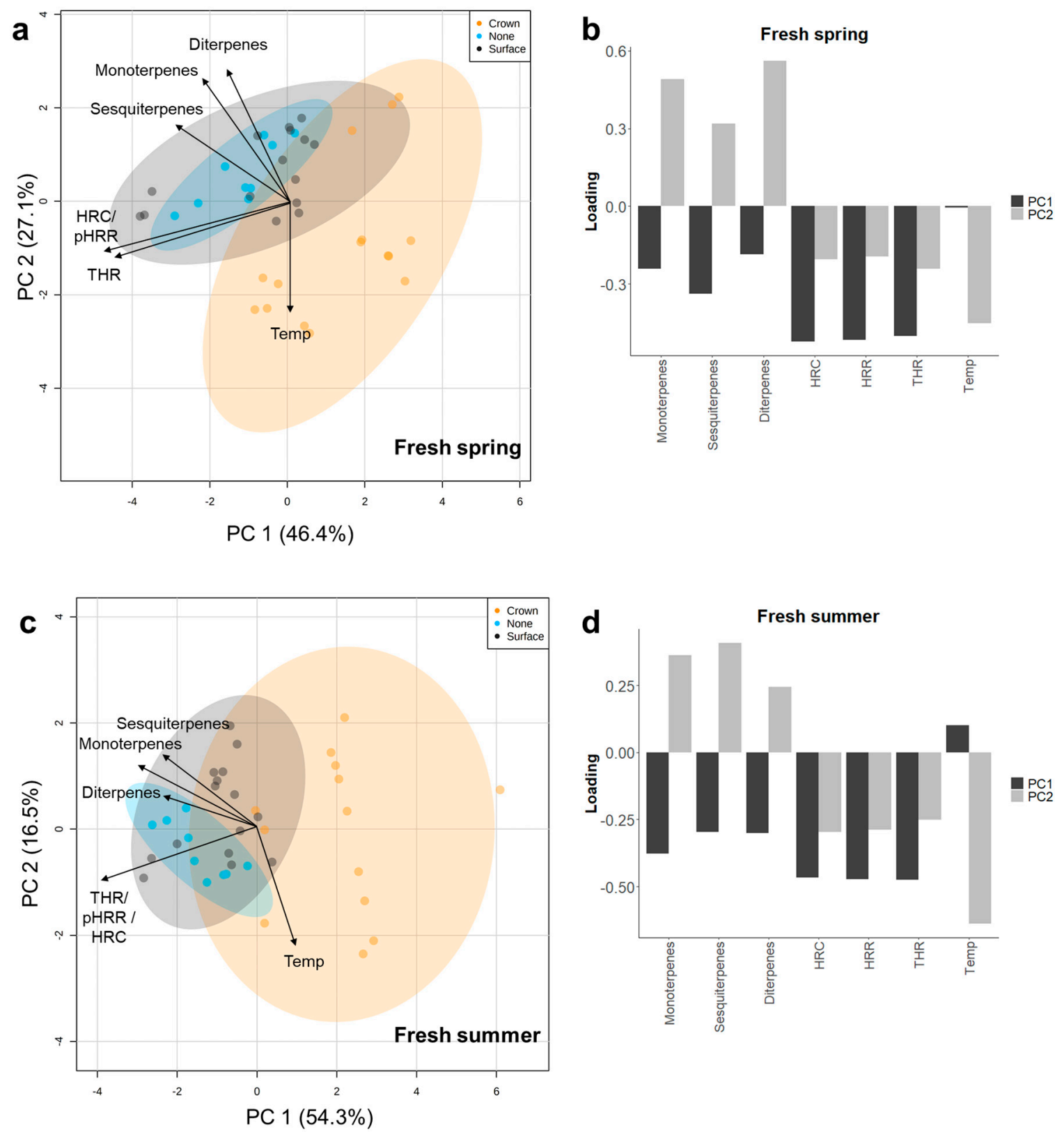

Figure 6. Principal component analysis (PCA) of flammability traits in fresh needles (a-d). Principal component analysis of the terpene content and flammability characteristics of fresh pine needles, sampled in spring (a) and summer (c). Crown-fire species are represented in orange, surface-fire in grey and none-fire in open circles. Each point represents an individual replicate, with three replicates per species, and $95 \%$ confidence intervals for each fire regime are shown with ellipses. The contribution of individual factors to the first two principal components are indicated with labelled arrows $(\mathbf{a}, \mathbf{c})$ and are shown in (b) for spring data and (d) for summer data.

We also assessed the flammability of lab-dried needles in a fuel bed packed to the natural packing density of the needles. This is representative of litter, which is important, as litter is most often the ignition point for both surface and crown fires. The needle litter of crown-fire species were similarly found to have a lower peak heat release rate $\left(364.6 \pm 13.0 \mathrm{~kW} / \mathrm{m}^{2}\right.$ compared to $\left.810.8 \pm 24.2 \mathrm{~kW} / \mathrm{m}^{2}\right)$ and lower total heat release $\left(2.93 \pm 0.02 \mathrm{MJ} / \mathrm{m}^{2}\right.$ compared to $\left.8.12 \pm 0.2 \mathrm{MJ} / \mathrm{m}^{2}\right)$ than surface-fire species (Figure $8 b, d$ ); the heat release parameters of non-fire species (peak heat release rate of $552.72 \pm$ $50.1 \mathrm{~kW} / \mathrm{m}^{2}$ and total heat release of $7.48 \pm 4.2 \mathrm{MJ} / \mathrm{m}^{2}$ ) were intermediate (Figure $8 \mathrm{f}$ ). These larger scale 
flammability measurements for surface and crown fires follow the same overall trend as the leaf-level flammability measurements (Figure S6). It is, however, interesting to note that the non-fire species lab-formed litter was considerably less flammable than those characteristic of surface fire regimes (Figure 8f), despite relatively small differences in total terpene and leaf-level flammability. The surface fire regime lab-formed litter burned with 1.6 times more peak heat release than that from the non-fire regime species. At the same time, the total heat release of the non-fire species was approximately half that of those from surface fire regimes (Figure 8).

a
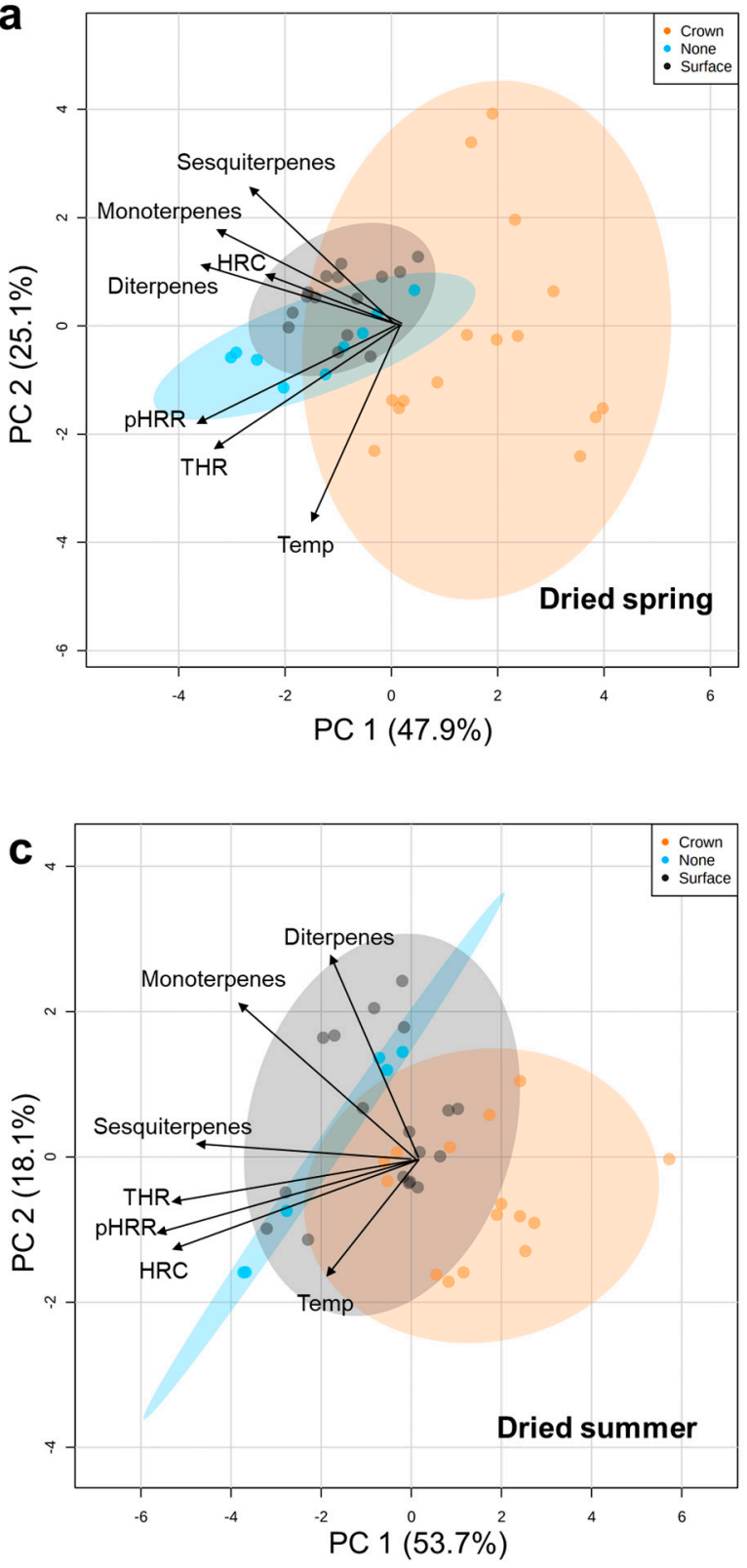

b

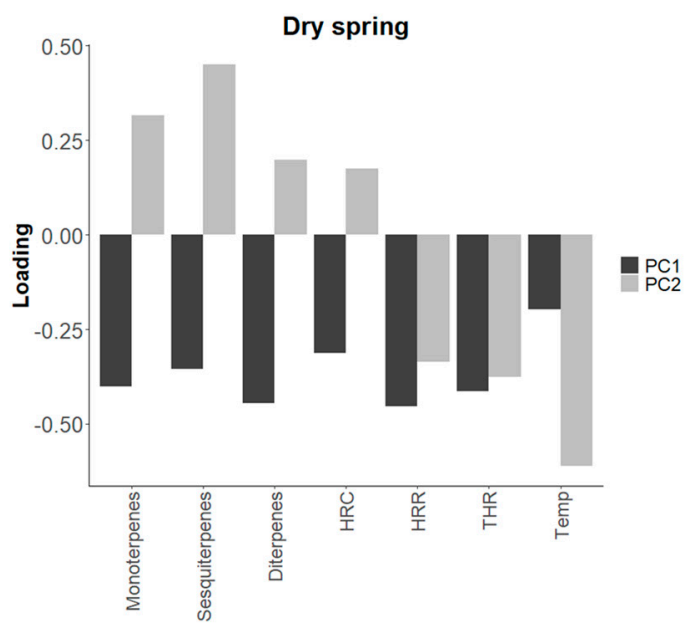

d

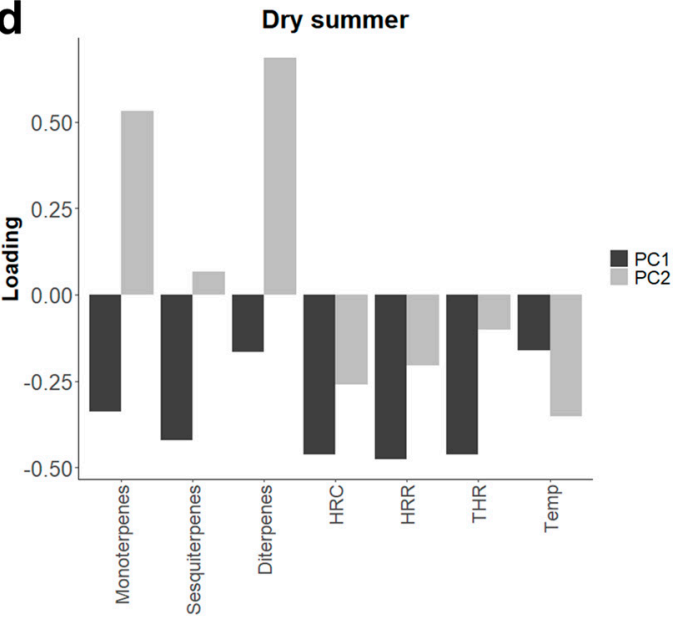

Figure 7. PCA of flammability traits in lab-dried needles (a-d). Principal component analysis of the terpene content and flammability characteristics of lab-dried pine needles, sampled in spring (a) and summer (c). Crown-fire species are represented in orange, surface-fire in grey and none-fire in open circles. Each point represents an individual replicate, with three replicates per species, and 95\% confidence intervals for each fire regime are shown with ellipses. The contribution of individual factors to the first two principal components are indicated with labelled arrows $(\mathbf{a}, \mathbf{c})$ and are shown in $(\mathbf{b})$ for spring data and (d) for summer data. 

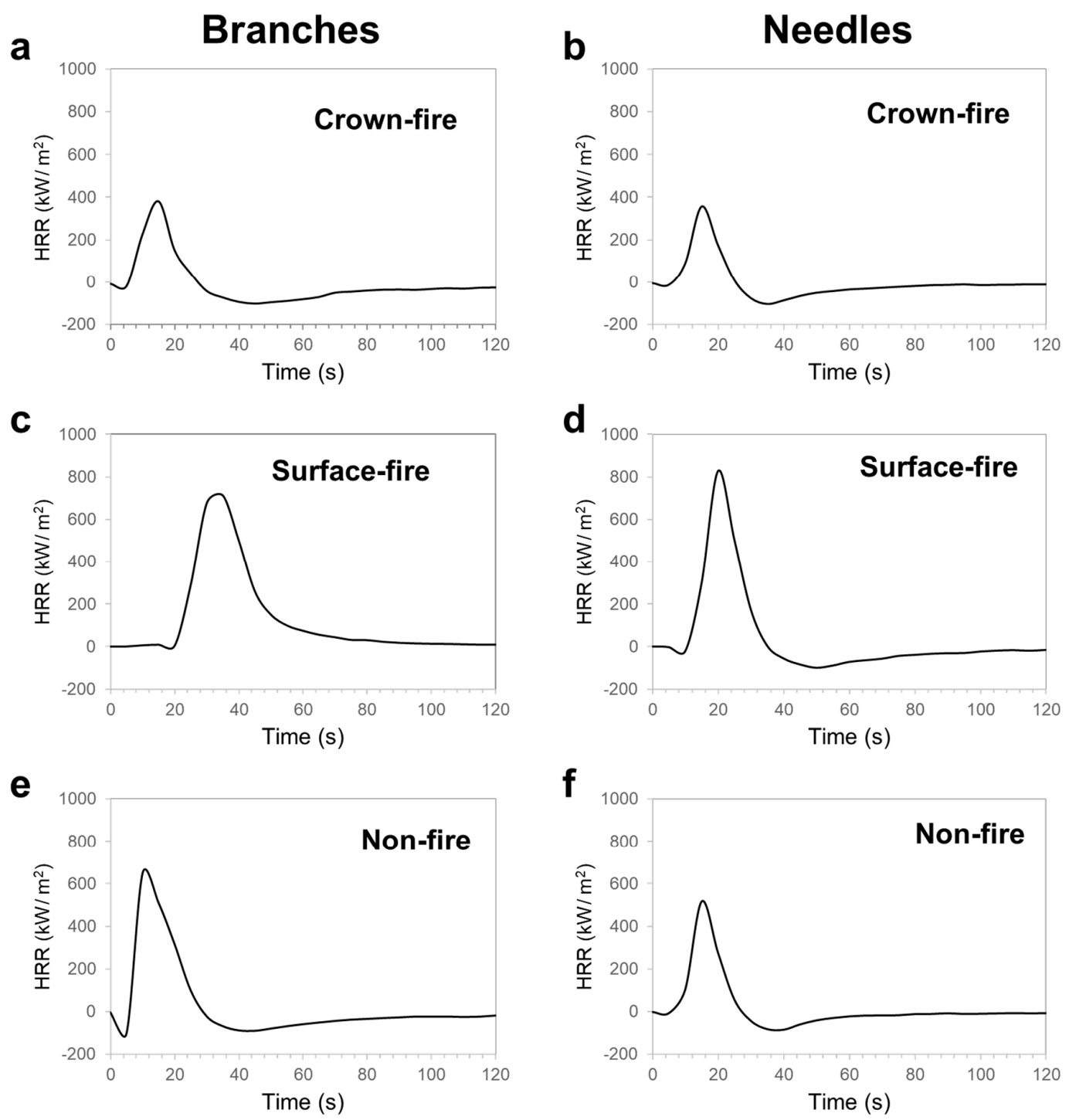

Figure 8. Heat release rate of lab-dried needles and branches across fire regimes. Heat release profiles of small branches (left) and needle beds (right) from either surface fire (a,b), crown fire (c,d) or non-fire $(\mathbf{e}, \mathbf{f})$, as measured by cone calorimetry, are shown. The examples shown are representative profiles from three independent replicate analyses.

\section{Discussion}

We found that surface-fire species have higher leaf terpene content than crown-fire species and that this correlated with higher leaf-level flammability and also corresponded with lab-formed litter-level and branch-level flammability. This finding suggests that high levels of terpenes may have been selected for in the leaves of surface-fire species and against in crown-fire species, however this would require genetic analysis for confirmation in the future. This supports hypotheses that propose that pines that have a fire tolerator syndrome have enhanced litter flammability [13], and that because these traits occur in a range of co-located pines, they may be evolutionarily very old [24]. Importantly, we are able to indicate that the enhancement of flammability in fire-tolerant pines is not only via traits that influence packing ratios and bulk density of the litter, but that this flammability is also driven by investing greater terpene contents in individual leaves.

Our data correspond with previous reports which show that higher flammability is linked to higher terpene content [5-7,32]. These previous studies generally focussed on intra-species variation, or variation between non-related species, whereas our study analysed variation between related 
species. Crucially, our study encompassed a range of species from the same genus native to different fire environments, and our data indicate that the species which are typically associated with crown fire are less flammable at the leaf-level than species found in surface-fire or non-fire regimes. While shoot flammability has recently been demonstrated to be phylogenetically conserved, the variability of flammability within the Pinus genus mirrors the shoot flammability variation observed in the Dracophyllum genus [33].

Traits that enhance flammability such as small leaves, volatile compounds (e.g., terpenes) and retention of dead leaves and branches are often cited as being characteristic of crown fire ecosystems [1]. This is suggested as being particularly important in the case of post-fire seedling recruitment in serotinous species (fire embracers), which are believed to have the most flammable canopies [1] and follow a hot-flammable strategy [12]. However, our study indicates that terpene content of dried pine needles is greatest in surface fire species and that this appeared to enhance flammability of individual leaves, lab-formed litter and branchlets more than in species native to crown fire regimes. This suggests that the assemblage of remains on the forest floor in fire tolerator communities will not only have leaves that have higher volatile driven flammability, but that this positively interacts with other factors that influence the flammability of the litter bed and that of shoots on abscised branches on the forest floor, such as leaf morphological traits and bulk density [6,9]. In the case of the non-fire pine species, the flammability of individual leaves was similar to those characteristic of surface-fire regimes, however, as branchlets and as lab-formed litter, the flammability of non-fire species was comparatively diminished. It seems that in the case of non-fire species, morphological traits override terpene-induced flammability at the leaf-level. We acknowledge that we tested only limited species for litter and branchlet-level flammability compared to those tested for individual leaf flammability, and so the litter and branchlet-scale tests should be interpreted with caution, but they are supportive of the leaf-level tests, and in accord with previous research [12,19].

We also analysed seasonal differences in terpene content and flammability and revealed that although there are differences, crown-fire species had consistently lower terpene levels and flammability than surface-fire species. Terpene content was lowest in spring, which corresponds to the native fire regime of many of the species investigated. This could suggest that fire-adapted species may regulate terpene content during fire season in order to influence fire behaviour.

Evolution of flammability implies selection for traits that influence the frequency or intensity of fires [1]. For example, [34] suggested that pine litter is more flammable than oak litter and that without fire, the pines would be replaced by oaks, whilst [35] proposed that enhanced flammability in fire-prone ecosystems ought to protect belowground organs and nearby propagules of plants during wildfires. This is because volatile-fuelled fires will burn more intensely (e.g., Figure 8b,d) and will therefore have a higher surface rate of spread, meaning that the heating duration at the ground's surface is shorter than in slower moving fires. This would be typical of 'fast flammable' strategies [12].

Pines that dominate in surface fire regimes tend to have traits that protect them from frequent surface fires, such as shedding of lower branches (self-pruning) to prevent surface fires climbing into the canopy, thick heat protective bark and epicormic resprouting [13,36,37]. Some have suggested that these 'fire-tolerator' pines have long needles that form less compacted litter than those with shorter needles [38]. These lower bulk density litters result in more intense litter fire [25,28,39]. Our results suggest that pine needles in surface fire regimes also have higher terpene contents, which additionally enhances the flammability of their litter beds (e.g., Figure 8), allowing them to carry more intense and more rapidly spreading surface fires. If the moderation of the terpene content of these surface fire regime pine needles is capable of altering the fire environment insomuch as it is favourable to the growth or establishment of the their offspring, then this could constitute a biochemical form of niche construction $[35,40]$.

The microcalorimetry method used here to determine biochemical leaf-level flammability removes the effect of leaf thickness and length, as samples are prepared by cutting into very small segments, thus allowing us to focus on the inherent biochemical drivers of flammability separate from morphology. 
Our results suggest that biochemical traits that speed up combustion (i.e., enhanced terpene content of needles) are capable of acting along with other morphological traits, such as leaf length and thickness, which influence litter bulk density and aeration, and branch shedding, to be directly advantageous to each individual carrying the fire tolerator syndrome. It has been argued that traits associated with increased flammability should reduce the likelihood of damage to a plant's belowground organs and propagules [35]. Such reduction in damage together with the nature of the post-fire environment would then work together to favour the pyrogenic plant's offspring. For example, in surface fire regimes, it is not beneficial for litter to accumulate over long periods as this would make the litter and duff layer highly vulnerable to smouldering fires [41,42] and a thick litter layer also makes germination more difficult [13]. In such a case, branch shedding traits would be of little advantage if tree boles and root-stock were subject to highly damaging smouldering fires. Therefore, enhancing the flammability of litter in such ecosystems, using both morphological and biochemical traits, would ensure that fires were frequent enough to remove litter accumulation but that the fires themselves moved rapidly enough to limit heat damage to the ground. As such, biochemical traits may be more important in influencing litter flammability (in pine surface fire regimes/fire tolerator syndromes) than in enhancing fire in pine crown fire (fire embracer syndrome) ecosystems. Therefore, it appears that surface fire dwelling pines have selected for high terpene contents because this provides a significant fitness gain; it would be beneficial to confirm this speculative hypothesis with genetic analysis. Our findings lend support to the theory proposed by Pausas [13] that surface fire pines (i.e., 'fire tolerators') have higher leaf litter flammability than crown fire species ('fire embracers'). It has also been suggested that this increased litter flammability, concurrent with relatively low tree-level flammability, of surface fire species is adaptive [12].

We suggest that if surface-fire species had the same terpene content as crown-fire species, the THR could be too low and may prevent regular surface fires that remove heavy understory. The occurrence of surface fires is important to pines in surface fire regimes to prevent shading out of their saplings by a thick understory, and seedling survival is enhanced after the removal of the litter layer by fire [43]. As such, we propose that terpene abundance has been selected for in fire-tolerating pines, in tandem with morphological traits, to moderate fire spread and intensity and enhance fire in surface fire regimes to prevent damage to root stocks and help engineer their growing space to provide their saplings with a competitive advantage. Hence, whilst the main role of terpenes is generally considered to be defence against pests [16], as well as communication between plants and other organisms as is likely the case for non-fire species, our analysis highlights a possible trade-off between the protective and fire-promoting roles of terpenes.

We note that crown fire regime pine species retain higher terpene contents than many other non-Pinus species; for example, the leaves of Pinus halepensis (a fire embracer) contain 1.5 times the amount of monoterpenes as Rosemarinus officinalis (a volatile rich shrub) [44]. Our findings should not be taken to indicate that fire embracers in crown fire regimes have low terpene contents that do not contribute to flammability. Indeed, it may well be the case that the lower terpene content and total heat release of crown-fire species may result in a lower spread rate and higher residence time, potentially leading to greater damage and loss of biomass. This would be beneficial for species adapted to stand-replacing fires, creating a more open environment for seedling establishment. However, we note that within this study, whilst we have analysed leaf-level flammability as well as small-scale lab-formed litter and branch level flammability, we have not assessed whole tree or community level flammability, due to feasibility and experimental constraints. It is likely that the canopy flammability of the fire embracer species tested scales differently from the leaf, branch and litter flammability [45,46], and that the results may vary between different genera. For instance, fire embracers can be flammable at the tree level but not necessarily at the leaf level [12] (although in the Pinus species tested here this is not the case). Moreover, leaf-level and shoot-level flammability were found to be decoupled in a study of 59 New Zealand indigenous species [47]. While we observed this decoupling with non-fire species, surface-fire and crown-fire species show similar flammability profiles at both the leaf and shoot 
level, although they would likely diverge at the canopy level. The difference in flammability between scales has been attributed to the physical arrangement of leaves within the litter bed [47]. However, leaf biochemical traits such as tannins [47], as well as terpenes [7], have been reported to correlate to litter-bed flammability, as we have demonstrated in the current study. Despite this, the finding that fire embracer pines have lower leaf-level flammability is important because it indicates that volatile content may play a less important role in crown fire regimes than plant architectural traits, canopy bulk density and live/dead fuel load proportions. For example, fire embracers occupying crown fire regimes have been suggested to have high standing dead biomass, moderate to high bulk density fuels, and high fuel continuity [12]. Indeed, [12] suggest that changes in individual flammability in pines is important in driving fire to the crown via branch retention or to the understory via self-pruning. It may be the case that the trait of branch retention has a greater influence on crown fire than the volatile content of individual leaves. Here, the branch retention trait will act not only as a fuel ladder to carry surface fires to the canopy, but will also tend to increase canopy bulk density, fuel load and, in the case of dead branch retention, dead fuel load. Together, these should enhance fire spread and intensity in fire embracers.

We note we have tested only a limited number of species, within the same genus, belonging to each fire regime. It would be valuable to repeat this experiment with trees that have experienced fire, to understand whether this pattern is maintained. It would also be valuable to repeat the experiment with trees in their native environments, as it is possible that growing the trees in an 'exotic' location in a 'common garden' experiment could affect terpene levels as well as flammability. Hence, ecophenotypic variations would be worth exploring in the future.

In conclusion, we argue here that increased leaf-level terpene concentration, in pine species that are native to surface fire regimes and are not serotinous, confers a direct fitness benefit (in terms of seedling competition). Therefore, in fire tolerator species in surface-fire environments, the terpene content of leaf litter appears to contribute to encouraging fire. We therefore suggest that pines that occupy surface-fire environments may have selected for the production of volatile and semi-volatile compounds in their leaves, because this trait acts to modify the fire environment at the local scale within the community, giving the pines competitive advantage to outcompete other plants in the sapling stage. Therefore, it is possible that leaf-level fire-related traits can operate in a myriad of directions to influence fire behaviour as a whole. Our data suggests that landscape-scale flammability in surface fire ecosystems is likely informed by both biochemical leaf-level traits and morphological traits that influence litter packing ratio and canopy bulk density. This highlights the need to understand the leaf-level flammability traits of fuels, as well as broader fire regimes, in the face of future climatic change because ecophysiological adaptations, including biochemical traits, are likely to impact leaf-level flammability. As such, our findings provide a strong argument that such parameters should not be overlooked if we are to attempt to fully understand the linkages between plant adaptive traits and fire, and their continued successful functioning in the face of global change.

Supplementary Materials: The following are available online at http://www.mdpi.com/2571-6255/3/2/17/s1, Figure S1: Example heat release profiles from two scales of flammability measurements, Figure S2: Total terpene content of pine species, Figure S3: Heat release capacity of pine species. Figure S4: Heat release profiles showing leaf-level flammability of pines from different fire regimes. Figure S5: Fuel moisture content measurements of fresh pine needles. Figure S6: Principal component analysis of terpene content and flammability of winter pine needles.

Author Contributions: Conceptualization, C.M.B. and R.A.D.; methodology, C.M.B., N.S. and R.A.D.; investigation, C.M.B. and R.A.D.; writing-original draft preparation, C.M.B., N.S. and R.A.D.; writing-review and editing, C.M.B., N.S. and R.A.D.; supervision, C.M.B. and N.S.; funding acquisition, C.M.B. All authors have read and agreed to the published version of the manuscript.

Funding: This research was funded through an ERC Starter Grant (grant number ERC-2013-StG-335891-ECOFLAM) awarded to C.M.B.

Acknowledgments: We thank Deborah L. Salmon (Exeter Biosciences Mass Spectrometry Facility) for GC-MS assistance and Mark Grosvenor for laboratory assistance. We thank the reviewers for constructive reviews and useful comments helping us improve the manuscript. 
Conflicts of Interest: The authors declare no conflict of interest. The funders had no role in the design of the study; in the collection, analyses, or interpretation of data; in the writing of the manuscript, or in the decision to publish the results.

\section{References}

1. Keeley, J.E.; Pausas, J.G.; Rundel, P.W.; Bond, W.J.; Bradstock, R.A. Fire as an evolutionary pressure shaping plant traits. Trends Plant Sci. 2011, 16, 406-411. [CrossRef]

2. Schwilk, D.W. Flammability is a niche construction trait: Canopy architecture affects fire intensity. Am. Nat. 2003, 162, 725-733. [CrossRef]

3. Rundel, P.W. Structural and Chemical Components of Flammability. In Fire Regimes and Ecosystem Properties: Proceedings of the Conference; Mooney, H.A., Bonnicksen, T.M., Christensen, N.I., Lotan, J.F., Reiners, W.A., Eds.; USDA Forest Service: Washington, DC, USA, 1981; pp. 183-207.

4. Papió, C.; Trabaud, L. Comparative study of the aerial structure of five shrubs of Mediterranean shrublands. For. Sci. 1991, 37, 146-159.

5. Pausas, J.G.; Alessio, G.A.; Moreira, B.; Segarra-Moragues, J.G. Secondary compounds enhance flammability in a Mediterranean plant. Oecologia 2016, 180, 103-110. [CrossRef]

6. Romero, B.; Fernandez, C.; Lecareux, C.; Ormeño, E.; Ganteaume, A. How terpene content affects fuel flammability of wildland-urban interface vegetation. Int. J. Wildland Fire 2019, 28, 614-627. [CrossRef]

7. Ormeño, E.; Céspedes, B.; Sánchez, I.A.; Velasco-García, A.; Moreno, J.M.; Fernandez, C.; Baldy, V. The relationship between terpenes and flammability of leaf litter. For. Ecol. Manag. 2009, 257, 471-482. [CrossRef]

8. De Lillis, M.; Bianco, P.M.; Loreto, F. The influence of leaf water content and isoprenoids on flammability of some Mediterranean woody species. Int. J. Wildland Fire 2009, 18, 203-212. [CrossRef]

9. Della Rocca, G.; Madrigal, J.; Marchi, E.; Michelozzi, M.; Moya, B.; Danti, R. Relevance of terpenoids on flammability of Mediterranean species: An experimental approach at a low radiant heat flux. iForest Biogeosci. For. 2017, 10, 766-775. [CrossRef]

10. Keeley, J.E. Ecology and evolution of pine life histories. Ann. For. Sci. 2012, 69, 445-453. [CrossRef]

11. Burger, N.; Bond, W.J. Flammability traits of Cape shrubland species with different post-fire recruitment strategies. S. Afr. J. Bot. 2015, 101, 40-48. [CrossRef]

12. Pausas, J.G.; Keeley, J.E.; Schwilk, D.W. Flammability as an ecological and evolutionary driver. J. Ecol. 2017, 105, 289-297. [CrossRef]

13. Pausas, J.G. Evolutionary fire ecology: Lessons learned from pines. Trends Plant Sci. 2015, 20, 318-324. [CrossRef] [PubMed]

14. Varner, J.M.; Kane, J.M.; Kreye, J.K.; Engber, E. The flammability of forest and woodland litter: A synthesis. Curr. For. Rep. 2015, 1, 91-99. [CrossRef]

15. Santoni, P.A.; Bartoli, P.; Simeoni, A.; Torero, J.L. Bulk and particle properties of pine needle fuel beds-Influence on combustion. Int. J. Wildland Fire 2014, 23, 1076-1086. [CrossRef]

16. Pichersky, E.; Gershenzon, J. The formation and function of plant volatiles: Perfumes for pollinator attraction and defense. Curr. Opin. Plant Biol. 2002, 5, 237-243. [CrossRef]

17. Fischer, N.H.; Williamson, G.B.; Weidenhamer, J.D.; Richardson, D.R. In search of allelopathy in the Florida scrub: The role of terpenoids. J. Chem. Ecol. 1994, 20, 1355-1380. [CrossRef]

18. White, C.S. Monoterpenes: Their effects on ecosystem nutrient cycling. J. Chem. Ecol. 1994, 20, 1381-1406. [CrossRef]

19. Pausas, J.G.; Moreira, B. Flammability as a biological concept. New Phytol. 2012, 194, 610-613. [CrossRef]

20. Moreira, B.; Castellanos, M.C.; Pausas, J.G. Genetic component of flammability variation in a Mediterranean shrub. Mol. Ecol. 2014, 23, 1213-1223. [CrossRef]

21. Pausas, J.G.; Alessio, G.A.; Moreira, B.; Corcobado, G. Fires enhance flammability in Ulex parviflorus. New Phytol. 2012, 193, 18-23. [CrossRef]

22. López-Goldar, X.; Villari, C.; Bonello, P.; Borg-Karlson, A.K.; Grivet, D.; Sampedro, L.; Zas, R. Genetic variation in the constitutive defensive metabolome and its inducibility are geographically structured and largely determined by demographic processes in maritime pine. J. Ecol. 2019, 107, 2464-2477. [CrossRef] 
23. Valor, T.; Ormeño, E.; Casals, P. Temporal effects of prescribed burning on terpene production in Mediterranean pines. Tree Physiol. 2017, 37, 1622-1636. [CrossRef] [PubMed]

24. He, T.; Pausas, J.G.; Belcher, C.M.; Schwilk, D.W.; Lamont, B.B. Fire-adapted traits of Pinus arose in the fiery Cretaceous. New Phytol. 2012, 194, 751-759. [CrossRef] [PubMed]

25. Cornwell, W.K.; Elvira, A.; van Kempen, L.; van Logtestijn, R.S.P.; Aptroot, A.; Cornelissen, J.H.C. Flammability across the gymnosperm phylogeny: The importance of litter particle size. New Phytol. 2015, 206, 672-681. [CrossRef]

26. Hummel, J.; Selbig, J.; Walther, D.; Kopka, J. The Golm Metabolome Database: A database for GC-MS based metabolite profiling. In Metabolomics; Nielsen, J., Jewett, M.C., Eds.; Springer: Berlin/Heidelberg, Germany, 2007; Volume 18, pp. 75-95.

27. Lyon, R.E.; Walters, R. A Microscale Combustion Calorimeter; Federal Aviation Administration William, J. Hughes Technical Centre, US Department of Transport: Washington, DC, USA, 2002.

28. Belcher, C.M. The influence of leaf morphology on litter flammability and its utility for interpreting palaeofire. Philos. Trans. R. Soc. B Biol. Sci. 2016, 371, 20150163. [CrossRef]

29. Belcher, C.M.; Hudspith, V.A. Changes to Cretaceous surface fire behaviour influenced the spread of the early angiosperms. New Phytol. 2017, 213, 1521-1532. [CrossRef]

30. Tewarson, A. Generation of Heat and Chemical Compounds in Fires. In SFPE Handbook of Fire Protection Engineering; National Fire Protection Association, Inc.: One Batterymarch Park, Quincy, MA, USA, 2002.

31. Alessio, G.A.; Peñuelas, J.; De Lillis, M.; Llusià, J. Implications of foliar terpene content and hydration on leaf flammability of Quercus ilex and Pinus halepensis. Plant Biol. 2008, 10, 123-128. [CrossRef]

32. Cui, X.; Paterson, A.M.; Wyse, S.V.; Alam, M.A.; Maurin, K.J.L.; Pieper, R.; Padullés Cubino, J.; O'Connell, D.M.; Donkers, D.; Bréda, J.; et al. Shoot flammability of vascular plants is phylogenetically conserved and related to habitat fire-proneness and growth form. Nat. Plants 2020, 6, 355-359. [CrossRef]

33. Bond, W.J.; Midgley, J.J. Kill thy neighbour: An individualistic argument for the evolution of flammability. Oikos 1995, 73, 79-85. [CrossRef]

34. Gagnon, P.R.; Passmore, H.A.; Platt, W.J.; Myers, J.A.; Paine, C.E.T.; Harms, K.E. Does pyrogenicity protect burning plants? Ecology 2010, 91, 3481-3486. [CrossRef]

35. Schwilk, D.W.; Ackerly, D.D. Flammability and serotiny as strategies: Correlated evolution in pines. Oikos 2001, 94, 326-336. [CrossRef]

36. Van Mantgem, P.; Schwartz, M. Bark heat resistance of small trees in Californian mixed conifer forests: Testing some model assumptions. For. Ecol. Manag. 2003, 178, 341-352. [CrossRef]

37. Fonda, R.W.; Belanger, L.A.; Burley, L.L. Burning characteristics of western conifer needles. Northwest Sci. 1998, 72, 1-9.

38. de Magalhães, R.M.Q.; Schwilk, D.W. Leaf traits and litter flammability: Evidence for non-additive mixture effects in a temperate forest. J. Ecol. 2012, 100, 1153-1163. [CrossRef]

39. Schwilk, D.W.; Kerr, B. Genetic niche-hiking: An alternative explanation for the evolution of flammability. Oikos 2002, 99, 431-442. [CrossRef]

40. Varner, M.J.; Gordon, D.R.; Putz, F.E.; Hiers, J.K. Restoring fire to long-unburned Pinus palustris ecosystems: Novel fire effects and consequences for long-unburned ecosystems. Restor. Ecol. 2005, 13, 536-544. [CrossRef]

41. Michaletz, S.T.; Johnson, E.A. How forest fires kill trees: A review of the fundamental biophysical processes. Scand. J. For. Res. 2007, 22, 500-515. [CrossRef]

42. Hille, M.; den Ouden, J. Improved recruitment and early growth of Scots pine (Pinus sylvestris L.) seedlings after fire and soil scarification. Eur. J. For. Res. 2004, 123, 213-218. [CrossRef]

43. Alessio, G.A.; Peñuelas, J.; Llusià, J.; Ogaya, R.; Estiarte, M.; De Lillis, M. Influence of water and terpenes on flammability in some dominant Mediterranean species. Int. J. Wildland Fire 2008, 17, 274-286. [CrossRef]

44. Fernandes, P.M.; Cruz, M.G. Plant flammability experiments offer limited insight into vegetation-fire dynamics interactions. New Phytol. 2012, 194, 606-609. [CrossRef]

45. Ganteaume, A. Does plant flammability differ between leaf and litter bed scale? Role of fuel characteristics and consequences for flammability assessment. Int. J. Wildland Fire 2018, 27, 342-352. [CrossRef] 
46. Alam, M.A.; Wyse, S.V.; Buckley, H.L.; Perry, G.L.W.; Sullivan, J.J.; Mason, N.W.H.; Buxton, R.; Richardson, S.J.; Curran, T.J. Shoot flammability is decoupled from leaf flammability, but controlled by leaf functional traits. J. Ecol. 2020, 108, 641-653. [CrossRef]

47. Grootemaat, S.; Wright, I.J.; van Bodegom, P.M.; Cornelissen, J.H.C. Scaling up flammability from individual leaves to fuel beds. Oikos 2017, 126, 1428-1438. [CrossRef]

(C) 2020 by the authors. Licensee MDPI, Basel, Switzerland. This article is an open access article distributed under the terms and conditions of the Creative Commons Attribution (CC BY) license (http://creativecommons.org/licenses/by/4.0/). 